control systems coexist not only in bacteria but also in eukaryotes. Recent work has provided a spate of information about negative regulation of eukaryotic genes, and it seems likely that repressor-like molecules play an important role in differentiation ${ }^{6}$. Furthermore, DNA sequences, called siiencers, with properties opposite to those of enhancers, have been described $^{7.8}$. Finally, we would like to stress that the interplay between regulatory proteins and multiple DNA targets through DNA-loop formation provides a very flexible framework for control and may well prove to be the clue for an understanding of other regulatory phenomena.

Gert Dandanell Karin HaMmER Institute of Biological Chemistry B, University of Copenhagen, Sølvgade 83, DK-1307 Copenhagen K, Denmark

Jens Erik Løve Larsen Poul Valentin-Hansen Department of Molecular Biology, University of Odense,

Campusvej 55,

DK-5230 Odense $M$,

Denmark

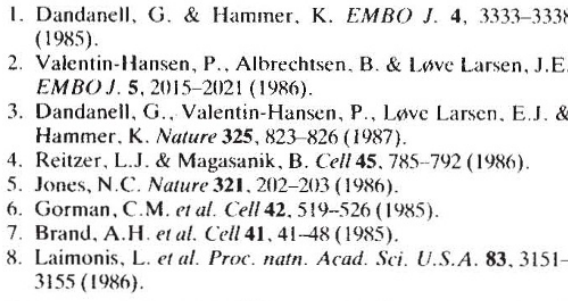

\section{Bamboo shortage not only cause of panda decline}

SIR-O'Brien and Knight in their article "The future of the giant panda" (Nature 325, 758-9; 1987) make a misleading statement which requires comment: "As a result of the flowering of the arrow bamboo in Wolong in 1983-85, 40-50 per cent of its pandas may have died and others may have emigrated".

There has been no mass starvation in Wolong. Neither the field biologists on the panda project nor the Chinese monitoring teams (who live in remote parts to find and assist debilitated pandas) have found evidence for such an event. In fact, field surveys - including my own-in various parts of Wolong revealed that patches of arrow bamboo survive throughout the area and also that pandas have alternative bamboo species available as food. In the project's main study area, pandas actually continued to subsist on arrow bamboo for three years after the die-off, showing food selectivity and activity patterns as before, until the winter of 1986-87 when some animals began to increase their use of the low-elevation umbrella bamboo. No evidence for emigration from the reserve exists; in any

SCIENTIFCCORRESPONDENCE

case, habitat conditions in neighbouring areas are no better than in Wolong.

The 1986 census of Wolong pandas revealed 72 animals, about half as many as a decade earlier. Whatever the precise figures, there has been a decline. What is the cause? During 1982-83, two and most probably three pandas in our small study population are known to have died in snares set by poachers for muskdeer. Such snaring was common in Wolong as well as in many other panda habitats both inside and outside reserves. Slow, constant attrition through snaring has no doubt been a major cause of the decline of Wolong's pandas and of those in various other areas.

Outside Wolong, a number of pandas starved as a result of the bamboo die-off in several small localities. China's captive population has increased greatly in recent years, with most pandas that were rescued during the die-off or otherwise captured having not yet been rehabilitated to the wild - as they should be, given the panda's poor breeding record in captivity. Taken together, the various factors can explain the overall decline in the number of pandas during the past decade. On completion of the current census in 1988, a reliable figure on the current status of the species will become available.

Conservation efforts must be based on accurate information and a recognition of priorities. Pandas are not timid and they readily adapt to the vicinity of humans. But they do need ample bamboo in relatively undisturbed forest habitat. And being a slowly reproducing species, the animals cannot maintain themselves under heavy hunting pressure. To preserve habitat, control poaching, and return many captives to the wild are three urgent conservation priorities.

George Schaller

New York Zoological Society,

Bronx Park,

New York 10460, USA

\section{Insects and Cretaceous mass extinction}

SIR-In the continuing debate ${ }^{1}$ on the reality and cause of the mass extinctions at the end of the Cretaceous, little attention has been paid to insect faunas. I should like to point out why comments on the "almost complete absence in the Cretaceous" of insect fossils are ill-founded, and how insect fossils can contribute to this debate.

Based on the morphology of living insects, most of the orders of insects and many of the families have been recognized in the Cretaceous. These include, for example, Formicidae (Hymenoptera), Aeshnidae (Odonata), Micropterigidae (Lepidoptera), Curculionidae (Coleoptera), Aphididae, Anthocoridae, (Hemiptera), Ceratopogonidae, Stratiomyidae (Diptera). These families, amongst many others known from the Cretaceous, have species which are common and widespread today. Most are well represented in the Cretaceous fossil record ${ }^{3-5}$ suggesting a widespread and abundant fauna. Across the Cretaceous/Tertiary $(\mathrm{K} / \mathrm{T})$ boundary the morphology of the individuals, and to a large extent the faunal composition, have changed little.

With their rapid reproductive rate and great powers of recovery, even over tens of years, is it possible that insects recovered so rapidly from a major catastrophe that changes in faunal composition at the $\mathrm{K} / \mathrm{T}$ boundary are so far undetected? What effect would the proposed meteorite impact ${ }^{6}$ have on insects?

Based on extant insect populations and on dividing the world insect fauna into three divisions - temperate northern, temperate southern and tropical latitudes - my answer is as follows. During the northern winter insects in the north will be in diapause, while Southern Hemisphere insects and those in the tropics will be active. Conversely, northern zone insects will be active during the southern winter. If a global period of cold and darkness following a meteorite impact lasted only a few months, insects in the winter latitudes could regard it as a 'late Spring' and remain in diapause for the extra months. In tropical forests the insect fauna, which does not have a comparable rest period, would be seriously affected, as would the insects in the summer latitudes. If the temperature and day lengths in the summer latitude were only gradually reduced after a meteorite impact, then insects in such regions might be able to respond by going into diapause. But even under these conditions the tropical insect fauna would be seriously depleted.

Assuming survival of insects in northern or southern temperate latitudes after a meteorite strike, the tropics would have to be recolonized by insects that survived in a temperate zone, a hypothesis for which there is no current evidence.

There is need for a closer study of the insect fauna across the $\mathrm{K} / \mathrm{T}$ boundary. At present the evidence points to survival of families, with apparently lower survival rate at the generic level and little or none at the species level. Lack of evolutionary change in the insects across the $\mathrm{K} / \mathrm{T}$ boundary argues against abrupt or catastrophic changes.

\section{Department of Entomology,}

Paul Whalley

British Museum (Natural History),

London SW7 5BD, UK

1. Officer, C.B., Hallam, A., Drake, C.L. \& Devine, D.D. Nature 326. 143-149 (1987)

. Hennig. W. Insect Phylogeny xxii 514 (Wiley, Chichester, 1981)

Whalley. P. Ann. Transv. Mus 31. 71-86 (1978)

4. Wilson, E.O. Carpenter, F.M. \& Brown, W.L. Jr Psyche 74. 1-19(1967)

McAlpine, J.F. \& Martin, J.E.H. Canad. Entomol. 101, 819-838 (1969)

Alvarez, L.W., Alvarez, W., Asaro, F. \& Michel, H.V. Science 208, 1095-1108 (1980). 